\title{
Complications of Kidney Biopsy in a Tertiary Hospital of Central Nepal, Chitwan
}

\author{
Madhav Ghimire, ${ }^{1}$ Shreeju Vaidya, ${ }^{1}$ Hari Prasad Upadhyay ${ }^{2}$ \\ ${ }^{1}$ Department of Nephrology, ${ }^{2}$ Department of Community Medicine, College of Medical Sciences Teaching Hospital, \\ Bharatpur, Chitwan, Nepal
}

\begin{abstract}
Background: Kidney biopsy is an important diagnostic tool in Nephrology and is said to be relatively a safe procedure.There are limited studies in the complications of kidney biopsy from this region. We therefore thought of looking into the complications of kidney biopsy and its risk factors.
\end{abstract}

\begin{abstract}
Methods: A hospital based analytical cross sectional study was carried out over a period of 3 years. Kidney biopsies were done under ultrasonography guidance. The complications and its risk factors were recorded and were analyzed using mean, standard deviation, ratio, percentage and chi square.

Results: A total of 210 patients were analysed. The mean \pm standard deviation of 210 patients was $35.7 \pm 14.9$ years. The commonest minor complication was biopsy site pain not requiring analgesics 136 $(64.8 \%)$ and the commonest major complication was biopsy site pain requiring analgesics $18(8.6 \%)$ followed by perinephric hematoma $10(4.8 \%)$. There was a significant association between low platelet count and the development of complications like pain requiring analgesic ( $\mathrm{p}$ value 0.04 ), perinephric hematoma ( $\mathrm{p}$ value 0.022 ) and gross hematuria ( $\mathrm{p}$ value 0.011 ).
\end{abstract}

Conclusions: Kidney biopsy is a safe procedure and low platelet count is a significant risk factor for complications ( $p$ value $<0.05$ ).

Keywords: complications; kidney biopsy; perinephric hematoma; platelet count.

\section{INTRODUCTION}

Kidney biopsy is an important invasive procedure in Nephrology. It is useful not only in diagnosis but also in the prognosis of the disease. ${ }^{1}$ It is known that invasive procedure has some inherent complications however the kidney biopsy is said to be a relatively safe and effective procedure with life-threatening complications occurring in less than $0.1 \%$ of biopsies. ${ }^{2,3}$ Previous study from Chitwan had also shown kidney biopsy to be a safe procedure. Kidney biopsies are regular procedure in various center but there are limited studies in the complications of kidney biopsy from this region. We therefore thought of looking into the complications of kidney biopsy procedure. This study was done with an objective to know the nature of the complications and the risk factors associate associated with the complication of the kidney biopsy in our center.

\section{METHODS}

This was a hospital based analytical cross sectional study carried out College of Medical SciencesTeaching Hospital, Chitwan over a period of 3 years from May 2016 to April 2019. All the consecutive kidney biopsies were included in the study. The approval to conduct the study was given by the Institutional Review Committee of the hospital and a written consent was taken from each patient prior to the biopsy procedure, after explaining the risk and benefit of the procedure and the possible complications of the procedure. The indication of kidney biopsies were the standard indication based on clinical presentation and investigations. Kidney biopsies were done by a nephrologist who had an experience of kidney biopsy for $>7$ years. A self-adjustable, automated, spring loaded gun biopsy needle of 16 to 18 gauge (Bard Monotopy USA 16-18 G) was used for kidney biopsy. Kidney biopsies were performed under ultrasonography (USG) guidance with the help of radiology residents or consultants. The lower pole of the kidney was identified for biopsy. Two cores of renal tissue were removed with maximum number of pricks not being more than four times. After the procedure, patients lay in bed flat on their back till they void their first urine and then remained in bed for $24 \mathrm{~h}$ of observation. Patients were monitored closely after biopsy for signs or symptoms of complications, such as flank pain requiring and not requiring analgesics, gross hematuria, need of blood transfusion or hypotension. The vital signs were checked every 15 min for $2 \mathrm{~h}$, every hour for $4 \mathrm{~h}$, every $2 \mathrm{~h}$ for 6

Correspondence: Dr. Madhav Ghimire, Department of Nephrology, College of Medical Sciences, Bharatpur, Chitwan, Nepal. Email: madhavghimirenp@yahoo.com. Phone: +977-9855060179. Article received: 2020-0225. Article accepted: $2020-06-02$. 
Ghimire et al. Complications of Kidney Biopsy in a Tertiary Hospital of Central..

$\mathrm{h}$, and then every $4 \mathrm{~h}$ thereafter. Each urine void post biopsy was checked for hematuria visually, and the results were recorded. Only those patients who developed pain over the biopsy site which was severe enough to require analgesics were followed up with USG scan to look for perinephric hematoma. The data including patient's demography, clinical renal syndromes and complications were recorded. The data were then entered and analyzed using SPSS version 20 (Chicago, IL, USA). The mean, standard deviation and chi square were used wherever applicable for statistical analysis.

\section{RESULTS}

A total of 210 kidney patients were analyzed over a period of 3 years. The mean $\pm \mathrm{SD}$ age of the patient was $35.7 \pm 14.9$ years. The age ranges of patients were from 9 years to 76 years. The mean $\pm \mathrm{SD}$ size of biopsy tissue obtained was $0.9 \pm 0.3 \mathrm{~cm}$. The minimum and the maximum size was 0.3 and $1.8 \mathrm{~cm}$ (Table 1).

\begin{tabular}{|c|c|c|}
\hline Table 1. Size of the bio & le. $(n=210)$ & \\
\hline Size of the biopsy tissue & Number & Percentage \\
\hline$<0.5 \mathrm{~cm}$ & 14 & 6.70 \\
\hline $0.5-1 \mathrm{~cm}$ & 106 & 50.50 \\
\hline$>1 \mathrm{~cm}$ & 90 & 42.90 \\
\hline
\end{tabular}

The average \pm SD number of glomeruli obtained was $23.4 \pm 11.03$. The minimum number was 2 and the maximum was 76 . Of total glomeruli $<20$ were seen in $94(44.8 \%)$, glomeruli $20-30$ were seen in 70 $(33.3 \%)$ and $>30$ were seen in $46(21.9 \%)$ (Table 2$)$.

\begin{tabular}{|c|c|c|}
\hline \multicolumn{3}{|c|}{$\begin{array}{l}\text { Table 2. Hb (Hemoglobin), Platelet count, Serum } \\
\text { creatinine, e-GFR (Glomerular Filtration Rate) and } \\
\text { Serum albumin of the patients. ( } n=210)\end{array}$} \\
\hline Hemoglobin (Hb) & Number & Percentage \\
\hline$<11 \mathrm{~g} / \mathrm{dl}$ & 94 & 44.80 \\
\hline$\geq 11 \mathrm{~g} / \mathrm{dl}$ & 116 & 55.20 \\
\hline \multicolumn{3}{|l|}{ Platelet count } \\
\hline$<100 \times 10^{9} / \mathrm{L}$ & 19 & 9.04 \\
\hline $150-350 \times 10^{9} / \mathrm{L}$ & 168 & 80.00 \\
\hline$>350 X 10^{9} / \mathrm{L}$ & 23 & 10.90 \\
\hline \multicolumn{3}{|l|}{ Serum Creatinine } \\
\hline$\leq 1.3 \mathrm{gm} / \mathrm{dl}$ & 111 & 52.90 \\
\hline$>1.3 \mathrm{mg} / \mathrm{dl}$ & 99 & 47.10 \\
\hline \multicolumn{3}{|l|}{ e- GFR } \\
\hline$<60 \mathrm{ml} / \mathrm{min}$ & 109 & 51.90 \\
\hline $60-90 \mathrm{ml} / \mathrm{min}$ & 22 & 10.50 \\
\hline$>90 \mathrm{ml} / \mathrm{min}$ & 79 & 37.60 \\
\hline \multicolumn{3}{|l|}{ Serum Albumin } \\
\hline$\leq 3.5 \mathrm{gm} / \mathrm{dl}$ & 152 & 72.40 \\
\hline$>3.5 \mathrm{gm} / \mathrm{dl}$ & 58 & 27.60 \\
\hline
\end{tabular}

The average serum creatinine was $2.2 \pm 2.5 \mathrm{mg} / \mathrm{dl}$. The minimum serum creatinine was $0.3 \mathrm{mg} / \mathrm{dl}$ and maximum serum creatinine was $18.1 \mathrm{mg} / \mathrm{dl}$ (Table 3 ). None of the patients developed hypotension or need of blood transfusion post biopsy and none of had mortality related to kidney biopsy (Table 4).

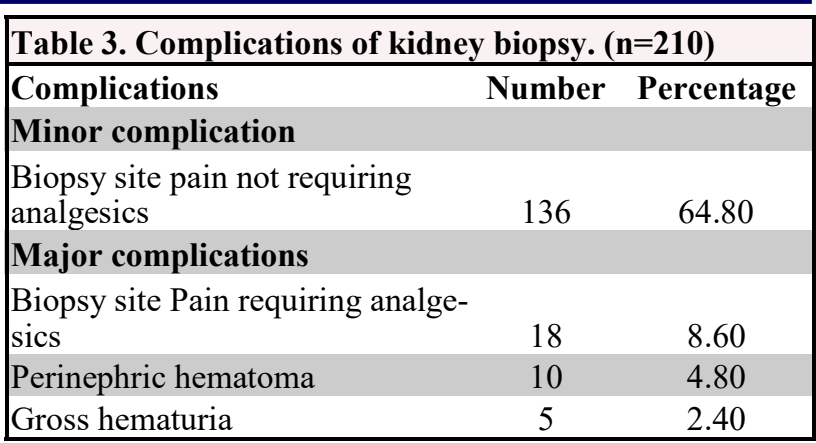

Table 4. Association between e-GFR, Hb and platelet with complication parameters $(\mathbf{n}=\mathbf{2 1 0})$.

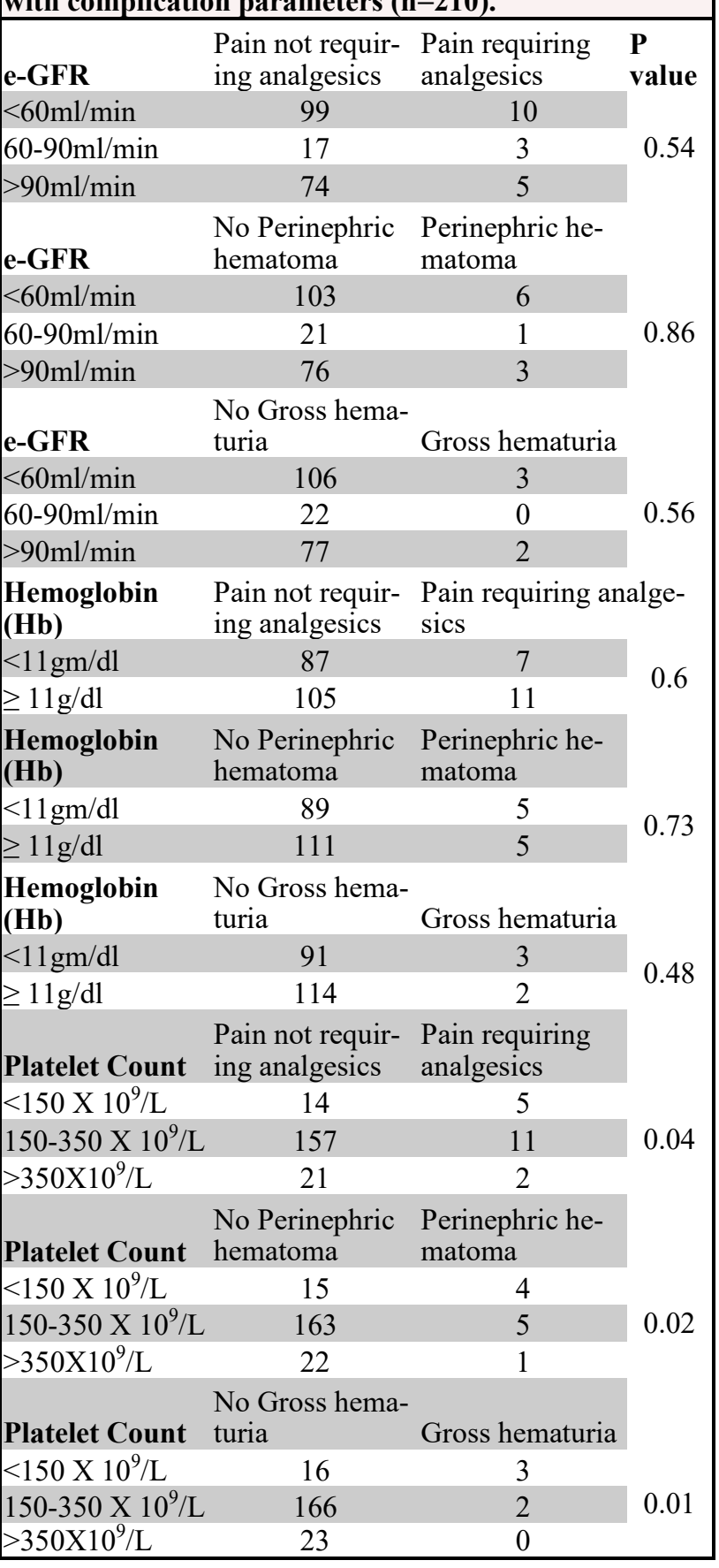

\section{DISCUSSION}

There are limited data on short term and long term complications of kidney biopsy from Nepal. In 
most of the studies done in complications of kidney biopsy from Nepal, the overall complications rate are low. ${ }^{4-8}$ The most common complication observed in our study was pain not requiring analgesics (minor complication) in $136(64.7 \%)$ patients. However the most common major complication was moderate to severe flank pain requiring analgesics in $18(8.6 \%)$ patients. Burnstein et al., reported complications in 91 $(14.3 \%)$ patients, out of which $6.6 \%$ were minor complications and rest were major. ${ }^{9} \mathrm{~A}$ study by Mendelssohn and Cole in their series found an overall complication rate of kidney biopsy to be $5.3 \% .{ }^{10}$ Similarly a study done by Tuladhar et al., ${ }^{6}$ showed the overall complication to be three (4\%).Other studies from Nepal done by Maskey et al., ${ }^{5}$ Manandhar et al., ${ }^{8}$ and Ghimire et al., ${ }^{4}$ showed gross hematuria as the commonest complication of kidney biopsy in $15(8.5 \%)$, six $(8 \%)$ and five $(6.7 \%)$ patients respectively. Perinephric hematoma was seen in $10(4.8 \%)$ patients in our study. However not all patients had routinely undergone USG evaluation to look for perinephric hematoma, which was one of the limitation of our study. Only those patients who had severe flank pain requiring analgesics $18 \quad(8.6 \%)$ had undergone USG evaluation to look for development of perinephric hematoma and of them $(n=18) 10$ were found to have perinephric hematoma. We adopted this approach to minimize the overall cost of kidney biopsy. Because of this, we could not establish the association between flank pain and the perinephric hematoma. This will be an area of future research.

In some other studies done by in Manandhar et al, ${ }^{8}$ Tuladhar et al., ${ }^{6}$ Ghimire et al., ${ }^{4}$ and Maskey et al., ${ }^{5}$ perinephric hematoma was seen in two $(2.67 \%)$ patients, three $(4 \%)$, four $(5.3 \%)$ patients and eight $(4.5 \%)$ respectively. According to a study done by Ralls et al., ${ }^{11}$ clinically significant perinephric hematomas was seen in $6 \%$ cases. We tried to look for the association between low e-GFR, hemoglobin level and platelet count and complications. In our study, $>50 \%$ had chronic renal insufficiency (e-GFR $<60 \mathrm{ml} / \mathrm{min}$ ) and we tried to see the association between low e-GFR and complications, however, there was no significant association between the low e-GFR $<60 \mathrm{ml} / \mathrm{min}$ and the complications like pain requiring the analgesia ( $\mathrm{P}$ value $=0.543)$, perinephric hematoma ( $\mathrm{p}$ value 0.860 ) and gross hematuria ( $\mathrm{p}$ value 0.569 ). However previous studies showed low e-GFR ${ }^{12-15}$ to be the predisposing factor for complications and the risk of bleeding increases with worsening renal function. ${ }^{12}$

In our study none of the patient needed any surgical or radiological intervention and none of the patient had hypotension or mortality. Similarly Maskey et al., ${ }^{5}$ Pandey et al., ${ }^{7}$ Ghimire et al., ${ }^{4}$ Manandhar et al. ${ }^{8}$ and Tuladhar et al., ${ }^{6}$ also did not report any cases of hypotension or biopsy related death. In a review done by Kobert SM in 9595 kidney biopsies over last 50 years, only $0.3 \%$ required major surgical or radiographic intervention and the mortality associated with the procedure was in < $0.1 \%$ of cases. ${ }^{16}$ Requirement of blood transfusion post procedure was not seen in our study. Similar observations were made by studies done by Ghimire et al., ${ }^{4}$ Manandhar et al. ${ }^{8}$ and Tuladhar et al. ${ }^{6}$ However three $(2.5 \%)$ patients required blood transfusion post biopsy in the study done by Pandey et $\mathrm{al}^{7}$ and in $1(0.6 \%)$ patient in the study done by Maskey et al. ${ }^{5}$

The average number of glomeruli and the average size of the biopsy tissue obtained in our study were $23.4 \pm 11.03$ and $0.9 \pm 0.3 \mathrm{~cm}$ respectively. A study from Romania done by Covic et al., ${ }^{17}$ showed that serious complications were more frequent when a large tissue fragments were harvested $(>20$ glomeruli). However we had not tried to see the association between the sizes of the tissue recovered and the number of pricks applied with the complications. This could be an area of future research. In our institute we do not recommend pricking more than 4 times. There was no significant association between the $\mathrm{Hb}$ level and the complications in our study however, there was significant association between low platelet count and the development of complications like pain requiring analgesic ( $\mathrm{p}$ value 0.04), perinephric hematoma ( $\mathrm{p}$ value 0.022 ) and gross hematuria $(\mathrm{p}$ value 0.011).Similar association between low platelet count and complication was seen in a study carried out over the 5-year period in 3,577 native kidney biopsies, where multivariable logistic regression analysis demonstrated low platelet count to be independently associated with the risk of complications. ${ }^{14}$ Likewise significant association between low platelet count and the risk of bleeding was seen in a study done by Monahan et al. $(\mathrm{p}=0.002){ }^{15}$

With the existing studies within and across the country ${ }^{4-8,16}$ and our study, it seems kidney biopsy is a safe procedure. However this was an observational study, so all the inherent limitations of observational studies were there in the study. This was a single center study so the results could not be generalized to the whole region or the country. We had not done the post biopsy USG in all the cases to minimize the cost, so we could not look for perinephric hematoma in all cases and the true prevalence of post biopsy perinephric hematoma was not represented and its association with the complications couldn't be established. We had not seen the association of age, sex, blood pressure, size of the biopsy needle (16 Vs. 18 gauge), number of pricks applied and the size of the 
biopsy tissue with the complication variables. We had also not seen the long term complication of kidney biopsy. These limitations demand another well structured, larger and multicentric study to better define the complications of kidney biopsy in our center and the country as a whole.

\section{CONCLUSIONS}

The kidney biopsy was a safe procedure and the low platelet count was a significant risk factor for complications $(\mathrm{p}$ value $<0.05)$. The overall complication rate was $18(8.6 \%)$. Kidney biopsy seems a safe procedure, so one should not hesitate to perform it whenever indicated. However, we need a large and multicentric study to understand the true prevalence of complications in the country.

\section{REFERENCES}

1. Tompson CRV. Indications for renal biopsy in chronickidney disease. Clinical Medicine. 2003; 3: 513-6.

2. Pesce F, Schena FP. Worldwide distribution of glomerulardiseases: the role of renal biopsy registries. Nephrol DialTransplant. 2010; 25: 334-6.

3. Whittier WL, Korbet SM. Timing of complications in percutaneous renal biopsy. J Am Soc Nephrol. 2004; 15: 142-7.

4. Ghimire M, Pahari B, Paudel N, Das G, Das GC, Sharma SK. Kidney Biopsy: An Experience from Tertiary Hospital. J Nepal Med Assoc 2014; 52: 707-12.

5. Maskey A, Lamsal L. Pattern of glomerular diseases in biopsy proven native kidney in Western Nepal. Journal of Advances in Internal Medicine. 2019;8(1): 5-8.

6. Tuladhar AS, Shrestha A, Pradhan S, Manandhar DN, Chhetri Poudyal PK, Rijal A et al. USG assisted and USG guided percutaneous renal biopsy at Nepal Medical College Teaching Hospital: A three and half years study. Nepal Med Coll J. 2014; 16: 26-9.

7. Pandey B, Sanjit Karki S, Shrestha R et al. Journal of Patan Academy of Health Sciences. 2017 Jun; 4(1):38-41.

8. Manandhar DN, Chhetri PK, Poudel P, Singh N, Baidya SK, Maskey A. Spectrum of glomerular diseases in native kidneys in patients attending Nepal Medical College Teaching Hospital. Journal of Advances in Internal Medicine. 2016; 5(2): 24-28.

9. Burstein DM, Korbet SM, Schwartz MM. The use of the automated core biopsy system in

percutaneous renal biopsies. A comparative study. Am J Kidney Dis.1993; 22:545-52.

10. Mendelssohn DC, Cole EH. Outcomes of percutaneous kidney biopsy, including those of solitary native kidneys. Am J Kidney Dis. 1995; 26: 580-5.

11. Ralls PW, Barakos JA, Kaptein EM et al: Renal biopsy related hemorrhage: Frequency and comparison of CT and sonography. J Comput Assist Tomogr.11: 1031-1034, 1987.

12. Diaz-Buxo JA, DonadioJV Jr: Complications of percutaneous renal biopsy: An analysis of 1,000 consecutive biopsies. ClinNephrol. 1975;4: 223 $-227$

13. Christensen J, Lindequist S, Knudsen DU, Pedersen RS: Ultrasound- guided renal biopsy with biopsy gun technique-efficacy and complications. Acta Radiol. 1995;36: 276-279.

14. Xu DM, Chen M, Zhou FD, Zhao MH. Risk Factors for Severe Bleeding Complications in Percutaneous Renal Biopsy. Am J Med Sci. 2017 Mar;353(3):230-235.

15. Monahan H, Gunderson T, Greene E, SchmitG, Atwell T, Schmitz J. Risk factors associated with significant bleeding events after ultrasound-guided percutaneous native renal biopsies: a review of 2204 cases. AbdomRadiol (NY). 2019 Jun;44(6):2316-22.

16. Korbet SM: Percutaneous renal biopsy. Semin Nephrol.2002; 22: 254-267.

17. Covic A, Schiller A, Volovat $C$ et al. Epidemiology of renal disease in Romania: a 10 year review of two regional renal biopsy databases. Nephrol Dial Transplant. 2006; 21:419-24.

Citation: Ghimire M, Shreeju V, Upadhyay HP. Complications of Kidney Biopsy in a Tertiary Hospital of Central Nepal, Chitwan. JCMS Nepal. 2020; 16(2):62-5. 